\title{
Precise performance:
}

DOI: $10.30636 /$ jbpa.11.19

\section{Do citizens rely on numerical precision as a cue of confidence?}

\section{Asmus Leth Olsen*}

\begin{abstract}
Recent research suggests that precise numbers signal confidence and are more potent anchors. This idea runs counter to the emphasis on simplicity in the presentation of performance numbers found in performance management and measurement research. Regardless, political-administrative systems are dominated by numerical information when it comes to evaluating performance or setting future performance goals. This article presents a set of experiments that test how well the precision effect translates in a political-administrative setting $(n=1,505)$. The findings provide no convincing evidence of a precision effect. Citizens' evaluation of performance numbers seems to be largely unaffected by the roundness or precision of their numerical value. This is the case even if the numerical information is presented without any explicit political cues or are framed as non-manipulative expert judgments.
\end{abstract}

Keywords: Performance management, Behavioral public administration, Performance information

"A false impression of accuracy can be created by quoting statistics in greater detail than is warranted by their precision or by overloading indicators with detail. [...] often used by politicians to impress with their grasp of detail..."

$$
\text { - Robert V. Horn (1993, p. 18) }
$$

$\mathrm{P}$ olitics is often a battle about numbers. Political-administrative actors state all sorts of facts, expectations, forecasts, performance metrics, or goals in order to win political arguments and gain support for their policies (Prewitt, 1987). With the rise of performance management and measurement in the public sector, numbers as an independent object of study enter the stage (Hood, 2007; Moynihan, 2008), or as Radin notes, "There is perhaps no element within the performance measurement process that is more important than the reliance on numbers and quantitative presentation of accomplishments" (2006, p. 27). Some have suggested that politicians might benefit from inflating their

\footnotetext{
* Department of Political Science, University of Copenhagen

Address correspondence to Asmus Leth Olsen at (ajlo@ifs.ku.dk)

Copyright: (C) 2018. The author licenses this article under the terms of the Creative Commons Attribution 4.0 International License.
}

stated confidence about numbers (Wildavsky, 1964; Radzevick \& Moore, 2011). Recent research suggests that one way of increasing citizens' confidence in numbers is by using more precise numbers (Janiszewski \& Uy, 2008; Thomas et al., 2010; Mason et al., 2013; Jerez-Fernandez et al., 2014; Zhang \& Schwarz, 2013). For instance, Mason et al. (2013) find that precise offers in negotiations are perceived as more informed which prompts less adjustment away from precise offers compared with round ones. In general, using any type of number has been found to boost citizens' competence ratings of politicians (Pedersen, 2017), even though performance information research finds that citizens themselves are more affected by episodic information than statistical information in their overall performance assessment of organizations (Olsen, 2017a).

In political-administrative settings, politicians and managers are the producers of numbers while citizens are the potential receivers (Yanic \& Foster, 1995, 1997; Radzevick \& Moore, 2011). If individuals prefer precise estimates, then number producers have strong incentives to supply precision (Radzevick \& Moore, 2011; Jerez-Fernandez et al., 2014). If citizens prefer precision over vagueness, it has very straightforward implications for how politicians should use numbers: be as precise as possible. Overly confident people tend to gain 
more influence (Koehler et al., 2002), and this effect could extend into politics. The open question is if "misplaced concreteness" (Horn, 1993, p. 18) and "specious accuracy" (Morgenstern, 1950, p. 3) in the form of precise political-administrative numbers can affect citizens in the same way as found in market place research.

In this article, we bring the recent insights on number precision in a market setting into the realm of politics. Across a set experiments we test how precise political-administrative numbers affect citizens' trust in forecasts, confidence in politicaladministrative decisions, and the likelihood of achieving future performance goals. The paper hereby adds to the discussion in performance management on the use and effect of performance data and goals (Moynihan, 2005; Rutherford \& Meier, 2015) and provides a potential piece in the puzzle of why managers not only use performance data (Moynihan \& Pandey, 2010) but also highly precise performance metrics. In general, performance management research has emphasized the importance of simplicity and parsimony in the presentation of performance data (Wholey \& Hatry, 1992; Holzer \& Yang, 2004). The simplicity of numerical performance information has the benefit of absorbing some of the uncertainties and assumptions of the underlying data (March \& Simon, 1958; Moynihan, 2008; Stone, 1997). Accordingly, recent research has emphasized the importance of comparisons and certain presentational formats as ways of easing citizens' reliance on quantitative performance data (Simon, 1939; Ammons \& Roegnigk, 2015; Olsen, 2017b). In short, performance management research offers some counter evidence to the benefits of more precise, and inadvertently more complex, forms of performance data.

Psychology also offers the expectation that political numbers as cues of confidence depend on citizens' beliefs about the number producer. Zhang and Schwarz $(2012,2013)$ find that the precision effect depends on the receiver's beliefs about the producer's cooperativeness. That is, precision has no effect if the producer is viewed as untrustworthy, self-interested, or incompetent. They draw on Grice's (1975) conversational logic which states that speakers apply a level of precision which reflects the accuracy of their knowledge. Hence the conversational norm in corporative conversations is to use less precision if uncertainty surrounds a numerical value. In a market place setting sellers or buyers might suspect that the conversational norms are broken in order achieve certain goals by signaling a high degree of certainty (Mason et al., 2013). Mason et al. (2013) speculate that precision can backfire if the receiver questions the producer's motives or expertise. There are also good reasons for citizens to be skeptical about the numbers that policy makers present. Previous research highlights that politicians can exploit cognitive biases in citizens' processing of numbers (Krishna \& Slemrod, 2003; Malhotra \& Margalit, 2010; Olsen, 2013). In summary, we have a performance measurement tradition which focuses on the value of numerical simplicity, while cognitive and social psychology offer reasons to believe that numerical precision can boost the impact of performance data but also that this effect might depend on the motives that citizens ascribe to the number producer. Below we will outline results from three experiments that estimate the effect of precision on citizens' reception of performance numbers in order to sort out the contrasting views of precision identified in recent work in psychology and the research on performance management and measurement.

\section{Data on Three Experiments}

The precision effect is tested across three independent experiments embedded in a single survey. Subjects for the survey were recruited via YouGov's Danish online panel $(\mathrm{n}=1,505)$. The data was collected between the 17 to 20 January in 2014. All subjects are between the ages of 18 to 74, and the sample is highly diverse in terms of age (M $=51.0, \mathrm{SD}=14.8)$, gender $(49.6 \%$ female $)$, education, and political party identification. Only half of the subjects were assigned to treatments in the first experiment $(n=749)$ while the other half was assigned to one of the treatments in the second experiment $(\mathrm{n}=756)$. In the third experiment all respondents were assigned to one of the treatments. The survey also contained a set of other unrelated studies that did not deal with numerical precision $(\mathrm{n}=1,505)$.

\section{Experiment 1: Choosing among Economic Predictions}

Governments and many other actors produce a large amount of forecasts of the economic and fiscal performance of political jurisdictions. The point 
of departure for the first experiment is to test if citizens have greater trust in precise numerical performance forecasts compared with less precise ones.

\section{Method}

One half of the subjects $(\mathrm{n}=749)$ were asked to choose between two different predictions about three different dimensions of the Danish economy in 2014 (the time the study was conducted). They were asked to choose the one they trusted the most. The dimensions covered (a) the economic growth rate, (b) the reduction in the number of unemployed, and (c) the state budget deficit. Subjects were randomly assigned to one of two conditions of the three dimensions. In the first condition the two predictions were a round number and a precise number slightly below the round numbers. For economic growth $1.5 \%$ and $1.463 \%$, for number of unemployed: 10,000 people or 8,750 people, and for the state budget deficit 20 billion (DKK) and 19.63 billion (DKK). In the second condition the subjects got the same round number along with a precise prediction of equivalent distance but slightly above the round estimate, all in the same order of magnitude as in the lower precise condition. The order of the two choices was randomized and sequence of the three prediction topics was also randomized. An exact translation of the experimental text and a screen cap of one of the treatments can be found in Appendix A.

\section{Results}

The overall results of the experiment is reported in figure 1 . For the growth rate in panel A, 51.6\% prefer the lower precise estimate of $1.463 \%$ over $1.5 \%$ (Binomial test $(\mathrm{n}=368), \mathrm{p}=.56)$. However, $76.4 \%$ prefer the round $1.5 \%$ if paired with the higher precise estimate (Binomial test $(\mathrm{n}=381), \mathrm{p}<.001)$. For the case of unemployment reduction in panel B, $72.8 \%$ pick the lower precise estimates over the round (Binomial test $(\mathrm{n}=381), \mathrm{p}<.001)$. On the other hand, $78.5 \%$ picked the round estimate when paired with a higher precise estimate (Exact binomial test $(\mathrm{n}=368), \mathrm{p}<.001)$. Finally, for the state budget deficit in panel $\mathrm{C}$ we observe a preference for the round estimate. When paired with a lower precise estimate, $54.9 \%$ chose the round estimate of 20 billion (Exact binomial test $(\mathrm{n}=381), \mathrm{p}=$ .068 ) and when paired with a higher precise estimate $57.7 \%$ picked the round 20 billion forecast (Exact binomial test $(\mathrm{n}=368), \mathrm{p}=.003)$. In summary, across all three scenarios no clear evidence points to the position that citizens mostly trust precise estimates over the round ones. In fact, subjects mostly choose the estimate with a negative outlook on the economy and with slight preference for round estimates. The former might indicate some motivated reasoning in numerical interpretation with a directional goal to discredit the current government (Bækgaard \& Serritzlew, 2016).

\section{Figure 1}

Two competing predictions about the Danish economy in 2014. Which one of these statements do you trust the most?
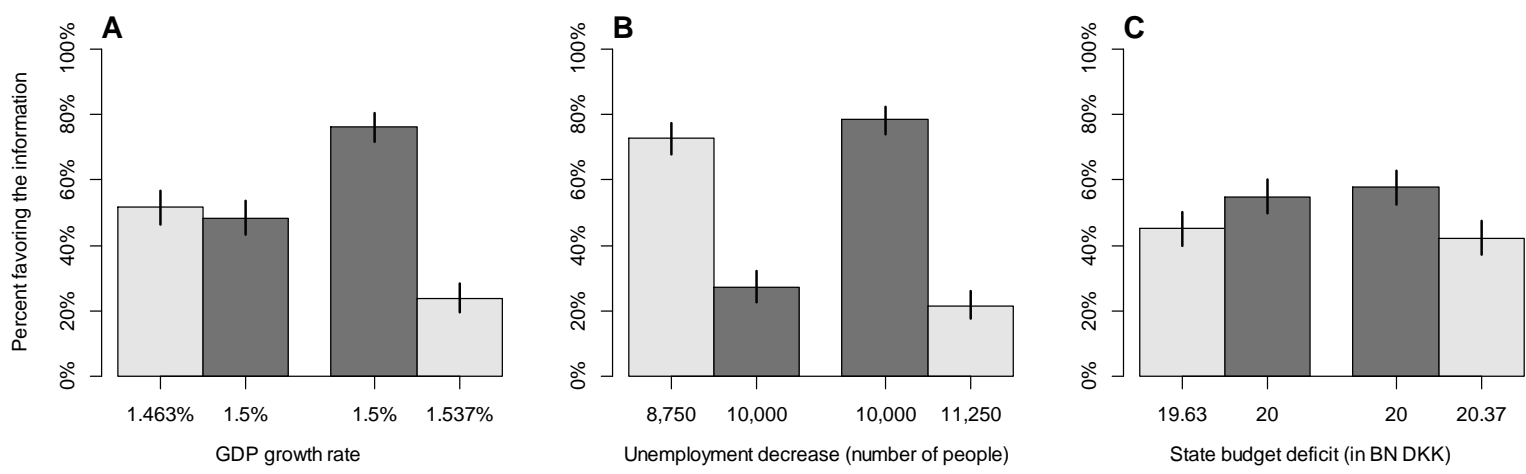

Note: Error bars indicate 95\%-confidence intervals 


\section{Experiment 2: Confidence in Performance Information}

In the second experiment we test how citizens rate their confidence in political-administrative numbers if precise and round estimates are evaluated in isolation. Asking subjects to rate their confidence in precise and round numbers is inspired by a similar study by Jerez-Fernandez et al. (2014) in which subjects rate their confidence in precise and round advices for quiz answers.

\section{Method}

Half of the subjects $(n=756)$ were asked to evaluate the information which informs various political decisions. They were asked to rate their degree of confidence in the information on an 11-point scale which ranged from 0 (no confidence) to 10 (very much). They provided their rating for three different pieces of performance information. The first condition contained political information with a round number while the second condition contained a precise number drawn from a pre-defined uniform distribution narrowly centered around the round number. Accordingly, some subjects re- ceived a precise estimate that was either slightly below or slightly above the round estimates assigned to the other treatment group.

One item of performance information stated that "The budget unit finds that the municipality needs to save 1,000 DKK per capita." In the precise condition the DKK amount was randomly drawn from a uniform distribution ranging from 901 DKK to 1,099 DKK (excluding 1,000 DKK). Another item of performance information was that "Experts find that economic growth in Denmark will be at $1.5 \%$ in 2014 " with precise estimates ranging from $1.401 \%$ to $1.599 \%$ (excluding $1.5 \%$ ). Finally, a statement read that "The Government expects the unemployment rate will decrease by 10,000 people in 2014" with precise estimates ranging from 9,001 to 10,999 (excluding 10,000). The order of presentation of the scenarios was also randomized, and subjects received only three precise estimates or three round estimates. An exact translation of the experimental text and a screen cap of one of the treatments can be found in Appendix B.

\section{Results}

Results of all three scenarios are shown in figure 2. First, for the municipal budget cuts in panel A the average confidence is same for both precise $(\mathrm{M}=$

Figure 2

Evaluation of the information which informs political decisions. How much confidence do you have in the correctness of this information?

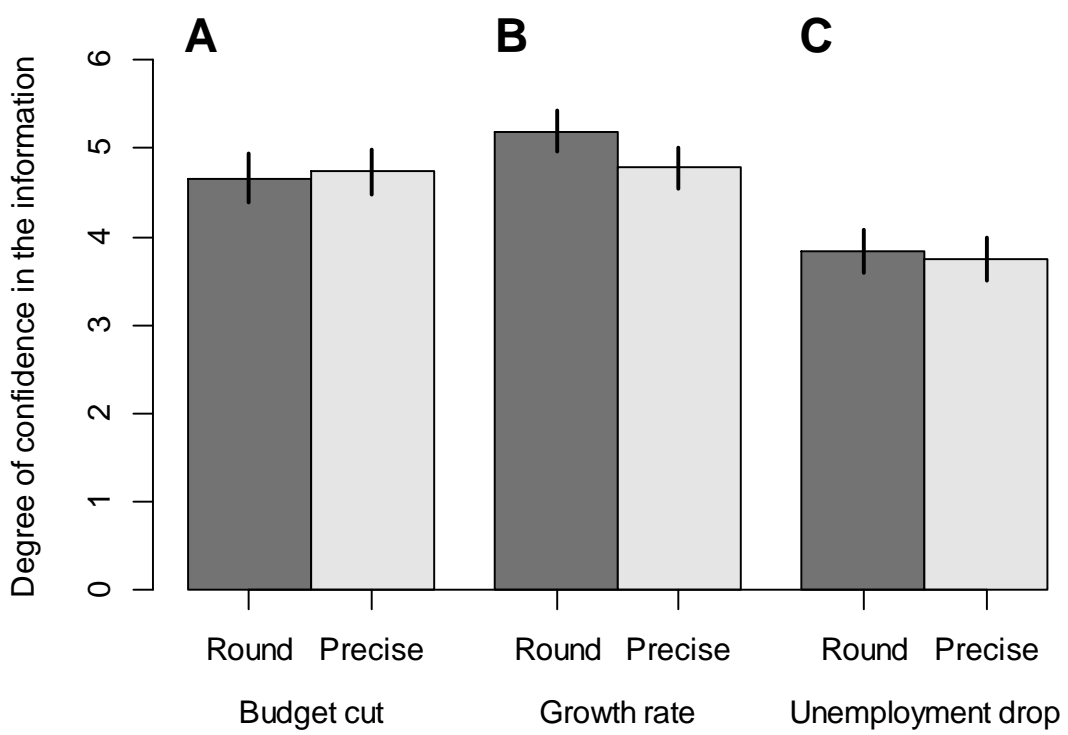

Notes: 11-point scale which ranged from 0 (no confidence) to 10 (Very much confidence). Error bars indicate 95\%confidence intervals. 
4.7, $\mathrm{SD}=2.5)$ and round $(\mathrm{M}=4.7, \mathrm{SD}=2.7)$ estimates $(t(754)=.38, \mathrm{p}=.70$, difference $=.06)$. For the case of the GDP growth rates in panel B, subjects have significantly more confidence in the round estimate $(\mathrm{M}=5.2, \mathrm{SD}=2.2)$ than the precise one $(\mathrm{M}=4.8, \mathrm{SD}=2.3),(\mathrm{t}(754)=2.5, \mathrm{p}=.013$, difference $=.42)$. Finally, for the decrease in unemployment in panel $\mathrm{C}$, the average confidence is also not significantly different at an average of 3.8 for both frames $(\mathrm{t}(754)=.42, \mathrm{p}=.67$, difference $=$ .08). Across all three scenarios we find either no difference between citizen confidence in precise and round estimates or in fact a slightly higher degree of confidence in round estimates.

\section{Experiment 3: The Likelihood of Achieving Performance Goals}

Long-term performance goals seem to play an important role in politics. However, citizens may be skeptical about politicians' ability and willingness to achieve goals that are beyond their own electoral career. In addition, these simple quantifiable goals often measure complex societal outcomes that can be difficult to affect, e.g., national wealth, the educational level of the population, human health, etc. In the final experiment we induce both more ambiguity and uncertainty into the performance goals by looking at long-term goals. In addition, we also vary the communicator's expertise and potential manipulative interests in presenting the numbers. We here draw on the finding in social psychology that precision matters if we believe the communicator has good intentions (Zhang \& Schwarz, 2012, 2013).

\section{Method}

All subjects $(\mathrm{n}=1,505)$ were assigned to one of two descriptions outlining how politicians set performance goals. The first frame emphasized that many performance goals often are set with the purpose of convincing the electorate: "Political goals are often set with help from political consultants who know how to convince voters." This frame was intended to induce the idea that performance goals are likely to be manipulative and highly strategic. The second frame emphasized the scientific soundness of many performance goals: "Political goals are often set with help from scientific experts who have great professional knowledge about the topic." This frame aimed at highlighting how performance goals can rest on expert judgment with non-manipulative intentions. Given the existing research, we would expect that precise performance goals only affect citizens more if they are provided by non-manipulative humans with some expertise (Zhang \& Schwarz, 2012, 2013). Subjects read three performance goals in random order. For each frame subjects were either assigned three policy goals with a round number or three policy goals with a precise number. The subjects were also only assigned to either manipulative or expert frames. The goals varied in terms of policy area and goal precision. The three goals in the round number frame were: (a) "By 2020 renewable energy must make up at least $30 \%$ of the total energy consumption," (b) "By 2020 public service expenditures must make up no more than $25 \%$ of the total economy," and (c) "By 2020 employment must be increased by at least 200,000 people." In the precise frame the numbers were drawn from a predefined distribution of round numbers in order to make the results robust to the different types of precise numbers. The energy policy goal was drawn from the interval from $29.01 \%$ to $30.99 \%$ and reported with two decimals (e.g., 29.67\%). The public expenditure interval was drawn from $24.01 \%$ to $25.99 \%$ and also reported with two decimals (e.g., 25.34\%). Finally, the employment goal was restricted to the interval from 191,001 to 209,999. Subjects were asked to rate the likelihood of achieving the stated policy goals on an unnumbered slider scale (101point scale ranging from 0 indicating "not at all likely" to 100 "very likely"). An exact translation of the experimental text and a screen cap of one of the treatments can be found in Appendix C.

\section{Results}

The overall results of the experiment are reported in figure 3. On average citizens assign a greater likelihood to the goals of renewable energy ( $\mathrm{M}=58.4$, $\mathrm{SD}=22.4)$ than in the two different economic goals (public expenditure: $\mathrm{M}=42.7, \mathrm{SD}=19.3$, employment: $\mathrm{M}=40.6, \mathrm{SD}=21.4)$. For all three scenarios we conducted a 2 (numbers: round vs. precise) X 2 (frame: manipulative vs. expertise) between subjects ANOVA with an interaction. For the case of the renewable energy goal in panel A, there is no significant interaction effect $(\mathrm{F}(1,1501)$ $=.59, \mathrm{p}=.44)$ but some weak evidence that the main effect of round goals is slightly positive $(\mathrm{F}(1$, $1505)=3.11, p=.078)$. For the case of the public 
Figure 3

The likelihood of achieving the stated policy goals. How likely do you believe it is that the following goal is achieved?
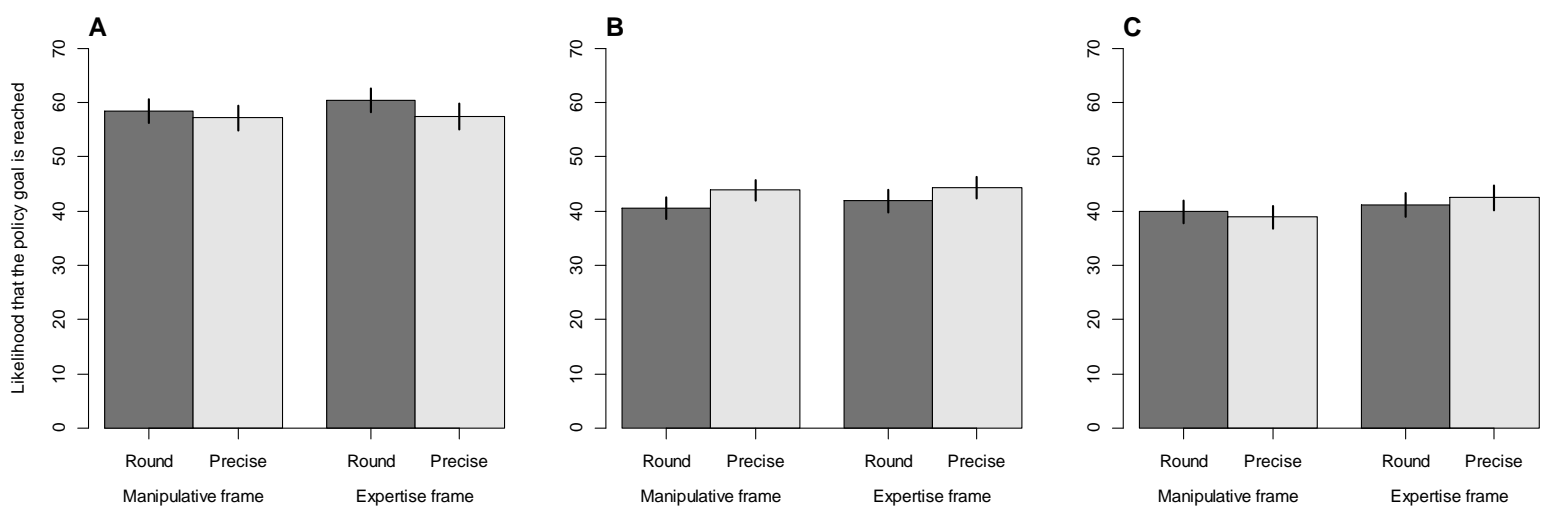

Notes: A 101-point scale ranging from 0 indicating "Not at all likely" to 100 "Very likely". A) "Goals on renewable energy," B) "Public expenditure goals," C) “Employment goals.” Error bars indicate 95\%-confidence intervals.

expenditure goal in panel $\mathrm{B}$ there is again no significant interaction effect $(\mathrm{F}(1,1501)=.19, \mathrm{p}=.66)$. There is also no main effect of the expertise frame $(\mathrm{F}(1,1501)=.80, \mathrm{p}=.37)$. However, we do find a positive main effect of numerical goal precision on citizens' likelihood assessment $(\mathrm{F}(1,1501)=8.42$, $\mathrm{p}<.01)$. However, we should take these results with some skepticism as the main effect of manipulative vs. expertise frame is close to zero which could indicate that the study failed to manipulate the cues about the information provider. This being said, a majority of subjects were able to recall the correct information provider. ${ }^{1}$ For the employment numbers in panel $\mathrm{C}$ there is also no significant interaction effect $(\mathrm{F}(1,1501)=1.16, \mathrm{p}=.28)$. There is a small positive main effect of receiving the expertise frame $(\mathrm{F}(1,1501)=4.7, \mathrm{p}=.029)$, but no main effect of numerical precision $(\mathrm{F}(1,1501)=$ $0.02, \mathrm{p}=.90)$.

\section{Discussion and Conclusion}

The three experiments reported on here aimed at extending research on numerical precision as a confidence cue in a political-administrative setting (Janiszewski \& Uy, 2008; Thomas et al., 2010; Mason et al., 2013; Jerez-Fernandez et al., 2014; Zhang \& Schwarz, 2013). The precision effect runs counter to a core emphasis on the value of simplicity in nu- merical performance data which is found in performance management and measurement research (March \& Simon 1956; Moynihan, 2008).

Across all experiments, including multiple different scenarios, we found no clear evidence of a precision effect in politics. In most instances the subjects did not rely on the roundness or precision of the numbers in their judgment. Citizens do not report greater trust or confidence in precise political numbers. They do not judge precise performance goals to be more likely to be achieved. And the effect does not depend on the motives of the goal provider as found in a market setting (Zhang \& Schwarz, 2012, 2013). Only for the case of numerical goals for future public expenditures did we find evidence of a small precision effect. It can be argued that the public expenditure measure is more difficult to encode and less often discussed in political debates. This may indicate that precision can play a role for numerical measures where citizens are more politically ambivalent.

This is by no means the definitive study of precision in political-administrative settings. A possible explanation for the null finding may be that subjects did not accept that the estimates were produced by another human which is an element important for a social attribution explanation (Zhang \& Schwarz, 2012, 2013; Jerez-Fernandez et al., 2014). That is, we could suspect that citizens who 
actively interact with others to seek out political advice would be more vulnerable to a precision effect. Also, we did not conduct additional analysis on selected subsets of subjects that, for instance, vary in education or interest in certain performance areas which could be an important moderator of the effects of precision. Different citizens will likely have different preferences for numerical precision and respond to performance data accordingly. It is also worth considering if some of the precision was almost superficially "precise." The randomly drawn precise numbers do provide some variation in the level of precision, and we have not looked further into if different types of precision have different effect.

In any case, the findings do suggest that precision cues are fragile outside of a market setting. This suggests that future research should look more into how the absence or presence of other cues crowd out the precision of a number as a relevant cue for citizens, voters, buyers, and all the other important roles in which humans make daily judgments about numerical performance.

\section{Acknowledgement}

I am grateful to the two reviewers, Kasper M. Hansen, Frederik Hjorth, Rasmus Tue Pedersen, Karina Pedersen, Yosef Bhatti, and participants and politics seminar at the University of Copenhagen for input on the experimental design. Support for the data collection was provided by grant 060202577B from the Danish Research Council.

\section{Notes}

1. At the end of the survey participants were asked to recall who usually provided politicians with goals according to the question they were exposed to earlier on. A list was provided with the two actual treatment options (political advisors or scientific experts) along with two unmentioned sources (party members and politicians from other countries) and a "don't know" option. $57.9 \%$ or 872 subjects provided a correct recall of the treatment.

\section{References}

Ammons, D. N., and Roenigk, D. J.. (2015).

Benchmarking and Interorganizational Learning in Local Government. Journal of Public Administration Research and Theory, 25, 309-35.

Bækgaard, M., and Serritzlew, S. (2016). Interpreting Performance Information: Motivated Reasoning or Unbiased Comprehension. Public Administration Review, 76(1), 73-82.

Grice, H. P. (1975). Logic and Conversation. In: Cole, P., and Morgan, J. L. (Eds.), Syntax and Semantics, 3: Speech acts (pp. 41-58). New York, NY: Academic Press.

Holzer, M., and Yang K. (2004). Performance Measurement and Improvement: An Assessment of the State of the Art. International Review of Administrative Sciences, 70(1), 15-31.

Hood, C. (2007). Public Service Management by Numbers: Why Does It Vary? Where Has It Come From? What Are the Gaps and the Puzzles? Public Money and Management, 27(2), 95-102.

Horn, R. V. (1993). Statistical Indicators: For the Economic and Social Sciences. Cambridge University Press.

Janiszewski, C., and Uy, D. (2008). Precision of the Anchor Influences the Amount of Adjustment. Psychological Science, 19(2), 121-127.
Jerez-Fernandez, A., Angulo, A. N., and Oppenheimer, D. M. (2014). Show me the numbers: Precision as a cue to others' confidence. Psychological science, 25(2), 633-635.

Koehler, D. J., Brenner, L., and Griffin, D. (2002). The Calibration of Expert Judgment: Heuristics and Biases Beyond the Laboratory. In: Gilovich, T., Griffin, D., and Kahneman, D. (Eds.) Heuristics and Biases (pp. 686-715). Cambridge University Press, Cambridge, UK.

Krishna, A., and Slemrod, J. (2003). Behavioral Public Finance: Tax Design as Price Presentation. International Tax and Public Finance, 10(2), 189-203.

Malhotra, N., and Margalit, Y. (2010). Short-Term Communication Effects or Longstanding Dispositions? The Public's Response to the Financial Crisis of 2008. Journal of Politics, 72(3), 852867.

March, J. G., and Simon, H. A. (1958). Organizations. New York: Wiley.

Mason, M. F., Lee, A. J., Wiley, E. A., and Ames, D. R. (2013). Precise offers are potent anchors: Conciliatory counteroffers and attributions of knowledge in negotiations. Journal of Experimental Social Psychology, 49(4), 759-763. 
Morgenstern, O. (1963). On the Accuracy of Economic Observations. Princeton: Princeton University Press.

Moynihan, D. P. (2005). Goal-based Learning and the Future of Performance Management. Public Administration Review, 65(2), 203-216.

Moynihan, D. P. (2008). The Dynamics of Performance Management: Constructing Information and Reform. Washington, DC: Georgetown University Press. Moynihan, D. P., and Pandey, S. K. (2010). The Big Question for Performance Management: Why Do Managers Use Performance Information? Journal of Public Administration Research and Theory, 20(4): 849866.

Olsen, A. L. (2013). The Politics of Digits: Evidence of Odd Taxation. Public Choice, 154(1-2), 59-73.

Olsen, A. L. (2017a). Human Interest or Hard Numbers? Experiments on Citizens' Selection, Exposure, and Recall of Performance Information. Public Administration Review, 77(3), 408-420.

Olsen, A. L. (2017b). Compare to What? How Social and Historical Reference Points Affect Citizens' Performance Evaluations. Journal of Public Administration Research and Theory, 27(4), 562-580.

Pedersen, R. T. (2017). Politicians Appear More Competent When Using Numerical Rhetoric. Journal of Experimental Political Science, 4(2), 129-150.

Prewitt, K. (1987). Public Statistics and Democratic Politics. In: Alonso, W., and Starr, P. (Eds.), The politics of numbers (pp. 261-274). New York: Russell Sage Foundation Publications.

Radin, B. (2006). Challenging the Performance Movement: Accountability, Complexity, and Democratic V alues. Washington, DC: Georgetown University Press.

Radzevick, J. R., and Moore, D. A. (2011). Competing to be Certain (But Wrong): Market Dynamics and Excessive Confidence in Judgment. Management Science, 57(1), 93-106.

Rutherford, A., and Meier, K. J. (2015). Managerial Goals in a Performance Driven System: Theory and Empirical Tests in Higher Education. Public Administration, 93(1), 17-33.

Simon, H. A. (1939). The Administrator in Search of Statistics. Public Management, 21, 106-9.

Stone, D. A. (1997). Policy Paradox: The Art of Political Decision Making. New York: W. W. Norton.

Thomas, M., Simon, D. H., and Kadiyali, V. (2010). The Price Precision Effect: Evidence from Laboratory and Market Data. Marketing Science, 29(1), 175-190.

Wholey, J. S., and Hatry, H. P. (1992). The Case for Performance Monitoring. Public Administration Review, 52(6), 604-610.

Wildavsky, A. B. (1964). Politics of the Budgetary Process. US: Little, Brown, and Company.

Yanic, I., and Foster, D. P. (1995). Graininess of Judgment Under Uncertainty: An Accuracy-
Informativeness Trade-Off. Journal of Experimental Psychology: General, 124(4), 424-432.

Yanic, I., and Foster, D. P. (1997). Precision and Accuracy of Judgmental Estimation. Journal of Behavioral Decision Making, 10(1), 21-32.

Zhang, Y. C., and Schwarz, N. (2013). The Power of Precise Numbers: A Conversational Logic Analysis. Journal of Experimental Social Psychology, 49(5), 944946.

Zhang, Y. C., and Schwarz, N. (2012). How and Why One Year Differs from 365 Days: A Conversational Logic Analysis of Inferences from the Granularity of Quantitative Expressions. Journal of Consumer Research, 39(2), 248-259. 


\section{Appendix}

\section{Appendix A: Study 1 - Experimental design}

Please evaluate different predictions about the Danish economy in 2014.

Which one of these statements do you trust the most?

The economic growth rate will be: a) $1.463 \%$ or b) $1.5 \%$.

The unemployment rate in Denmark will decrease by: a) 8.750 people or b) 10.000 people

The state budget deficit will end up at: a) 19.63 bio. (DKK) or b) 20. bio. (DKK).

\section{Figure 4: Example screen from experiment 1}

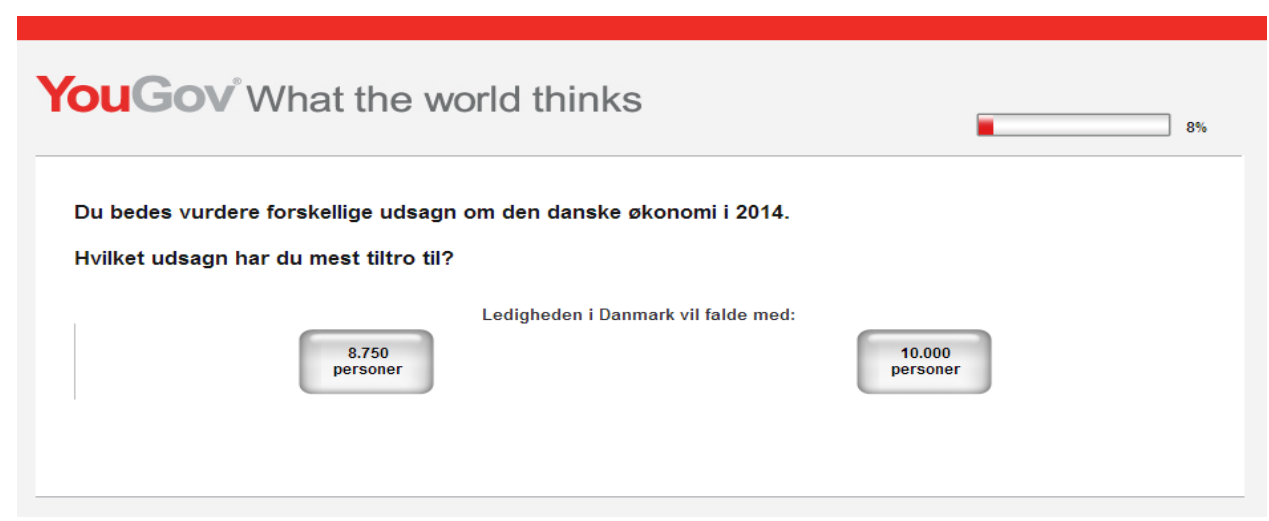

\section{Appendix B: Study 2 - Experimental design}

Please evaluate the information which informs political decisions.

How much confidence do you have in the correctness of this information?

The budget unit finds that the municipality needs to save 1,000 DKK per capita.

Experts find that economic growth in Denmark will be at 1.5\% in 2014

The Government expect the unemployment rate will decrease by 10,000 people in 2014

\section{Figure 5: Example screen from experiment 2}

\section{YouGov What the world thinks}
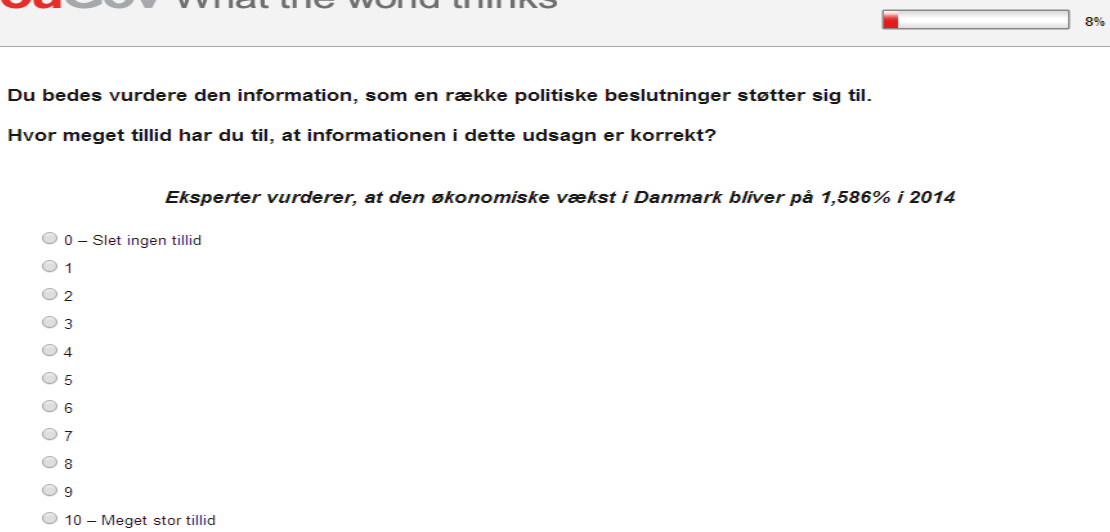

10 - Meget stor tillid 


\section{Appendix C: Study 3 - Experimental design}

The politicians set many goals for how Denmark should develop in the future.

These political goals are often set with help from political consultants who know how to convince voters.

\section{$[\mathrm{OR}]$}

These political goals are often set with help from scientific experts who have great professional knowledge about the topic.

How likely do you believe it is that the following goal is achieved?

By 2020 renewable energy must make up at least 30\% of the total energy consumption.

By 2020 public service expenditures must make up no more than $25 \%$ of the total economy

By 2020 employment must be increased by at least 200.000 people.

Figure 6: Example screen from experiment 3

\section{YouGov What the world thinks}

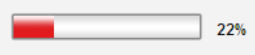

Politikerne sætter mange mål for, hvordan Danmark bør udvikle sig i fremtiden.

De politiske mål er ofte blevet til med hjælp fra politiske rảdgivere, der ved, hvordan man overbeviser vælgerne.

Hvor sandsynligt mener du, det er, at følgende mál kan opfyldes?

I 2020 skal vedvarende energi udgøre mindst $29,34 \%$ af det samlede energiforbrug 